\title{
OPENING REAL SCIENCE: STATISTICAL LITERACY FOR PRE-SERVICE PRIMARY TEACHERS THROUGH FLEXIBLE DELIVERY
}

\author{
Ayse Aysin Bilgin $^{1}$, Carmel Coady ${ }^{2}$, Joanne Mulligan ${ }^{1}$, Vincent Geiger $^{3}$, \\ Michael Cavanagh ${ }^{1}$, Peter Petocz ${ }^{1}$, Liz Date-Huxtable ${ }^{2}$ \\ ${ }^{1}$ Macquarie University, Australia \\ ${ }^{2}$ University of Western Sydney, Australia \\ ${ }^{3}$ Australian Catholic University, Australia \\ ayse.bilgin@,mq.edu.au
}

\begin{abstract}
Opening Real Science (ORS) is an Australian Government funded project in which leading teacher educators, scientists, mathematicians, statisticians and ICT designers are collaborating to develop online modules for implementation in teacher education programs, aimed at building the competence and confidence teachers need to inspire their students. This paper documents the development of a Statistical Literacy module for Primary Teachers (SL-P). The project's approach focusses on real life applications of statistics that students are genuinely interested in, coupled with scaffolding applications of digital technologies. An enquiry-based model supports the design of learning activities, which include appropriate resources to support individual and peer learning. Trials of the module will provide feedback on the effectiveness of the SL-P module in terms of student engagement and development of statistical literacy. The outcomes of the study will provide direction for re-shaping teacher education programs and professional learning to include statistical literacy as a core component.
\end{abstract}

\section{BACKGROUND}

Declining uptake of science and mathematics study in Australian schools has been attributed partly to a national shortage of appropriately trained teachers and partly to uninspiring teaching (Chubb, Findlay, Du, Burmester, \& Kusa, 2012). Recent international comparisons of mathematics and science achievement at high school level show a steady increase in the number of nations now outperforming Australia (Chubb et al., 2012). In addition, rural, remote, and indigenous students score well below metropolitan students, (Australian Government, Department of Employment and Workplace Relations, 2010). Years 7-10 of schooling are a crucial period in the formation of science attitudes, but less than half the number of teachers at this level have studied science for two or more years at university (Prasad, 2012; Tytler, 2007). Few primary teachers currently feel confident teaching science; consequently science occupies on average only $2.7 \%$ of teaching time in primary schools (ACARA, 2013).

The Opening Real Science (ORS) project aims to improve the quality of mathematics and science education and outcomes in Australia by engaging pre- and in-service teachers, particularly those entering the primary school system (Mulligan, Hedberg, Parker, Coady \& Cavanagh, 2014), in the concepts of authentic or Real Science (Braund, \& Reiss, 2006; Ziman, 2000). In addition, it aims to embed an understanding of the role of mathematics in scientific processes (Matthews, Belward, Coady, Rylands, \& Simbag, 2012). ORS is a unique collaboration between leading teacher educators, scientists, mathematicians, statisticians and ICT designers aimed at improving teacher education in mathematics and science. The ORS project is developing online modules for implementation in teacher education programs aimed at building the competence and confidence teachers need to inspire their students. It will develop and deliver modules across Mathematics, Physics (including astronomy), Chemistry, Biology, and Earth and Environmental science that embody the Real Science approach.

This paper documents the development process of a Statistical Literacy Module for Primary Teachers (SL-P), from its conception to its trials. The project's approach focuses on student-centred learning, employs problems that students are genuinely interested in where investigative approaches are employed in the classroom, coupled with scaffolding applications of digital technologies (Bower, Hedberg, \& Kuswara, 2010). An enquiry-based model based on the 5 Es framework (engage, explore, explain, elaborate, evaluate, Bybee, 2009) supports the design of learning activities with appropriate resources to support individual and peer learning.

In: M.A. Sorto (Ed.), Advances in statistics education: developments, experiences and assessments. Proceedings of the Satellite conference of the International Association for Statistical Education (IASE), July 2015, Rio de Janeiro, Brazil. (C)2015 ISI/IASE iase-web.org/Conference_Proceedings.php 


\section{MODULE DEVELOMENT}

Six mathematicians and mathematics educators and one educational developer from three universities (Macquarie University, University of Western Sydney, Australian Catholic University) contributed to the development of Statistical Literacy-Primary (SL-P). The module team's brief was to encapsulate the 5Es framework of enquiry-based learning (Bybee, 2009), such that storyboarding of the module was organized around the engage, explore, explain, elaborate and evaluate phases of the framework. The module would be seated in authentic settings, in which statistics are used by teachers. In theory such settings provide greater opportunity for a sixth ' $E$ ', 'elucidate', to occur (Mulligan \& Hedberg, personal communication). Module team members were asked to provide ideas and resources for activities and small assessment tasks that could be delivered in online format, as group and individual activities, in addition to developing a succinct set of learning outcomes. The module was then constructed as a narrative by the educational developer, using a backward faded scaffolding approach (Slater, Slater \& Shaner, 2008). Finally, the narrative was transferred to a learning management system site (moodle) by an educational designer. The resulting online module comprised five topics, Using Statistics in the Real World, Key Concepts in Statistical Literacy, Critiquing Statistical Claims, Using Statistical Reasoning and Presenting and Evaluating Evidence. The SL-P module was also required to be equivalent to 36-40 hours of study at the undergraduate level or approximately one third of a semester unit.

\section{Engage Phase: Using Statistics in the Real World}

Learning Outcome: Explore how statistics are used in the real-world

Initially students are asked to think about the use of statistics in their lives using a discussion forum with stimulus questions:

- What do you think statistics is?

- Why do you want to learn about statistics?

- How do you think you would best learn about statistics?

- What role do you think that statistics can play in your professional work as a teacher?

- What role do you think statistics can play in everyday life?

Four videos are used to engage students' interest in the presence of statistics in people's

lives. They view (online) an interview with statistician, Professor John Croucher, United Nations Economic Commission for Europe video entitled, "What is Statistics?", and Gapminder videos with Hans Rosling entitled, "200 Countries, 200 Years in 4 Minutes" and "Don't Panic: the Facts about Population". Students are then asked to discuss in another forum:

- What aspects of statistics are mentioned in the videos?

- Do you think that videos such as these would help you to learn more about statistics? Please give reasons for your answer

- What aspects of statistics could be interesting for your students and why?

- What role do you think statistics can play in the development of a sustainable future for the World?

The aim of the first discussion forum is to gauge the background range of students' statistical literacy. The videos then identify examples of professional uses of statistics in education and other professions and include some rich graphical visualisations of the data discussed. The second discussion forum prompts the students to make interpretations of data in the videos and to think about their relevance in a classroom setting.

\section{Explore Phase: Key Concepts in Statistical Literacy}

Learning Outcome: Calculate and interpret key statistical concepts needed in analysing a dataset

By using demonstration datasets of Australia's national numeracy testing (NAPLAN: National Assessment Program - Literacy and Numeracy) for years 3 and 5, the module then seats the pre-service teachers in an area of immediate interest for their future profession. The module links them to the NAPLAN demonstration site where they can explore and become familiar with the various categories of numeracy data collected and visual representations of these. It then asks the students to select 30 year 3 students' results from the demonstration dataset, calculate 
descriptive or summary statistics and post answers to four questions in a discussion forum, which include their evidence as calculated from and visualised by the data:

- What areas of numeracy are examined?

- What areas does the year 3 class appear strong/weak in?

- How can you tell?

- What conclusions can you make about the numeracy results of this class?

This activity is complemented by a resource window at the beginning of the module, which links them to videos and websites on how to calculate descriptive statistics and create graphs in Microsoft Excel and how to interpret them. There are also a broad range of optional resources that extend their exploration of statistical concepts. The assessment for this topic is to explore a dataset from the year 5 demonstration set in a similar manner and submit their results, both numerical and graphical representations, (online) in a brief 1-2 page report. This assessment gauges how well students have grasped these procedures and understood their meaning by replicating the activity with a different dataset.

\section{Explain Phase: Critiquing Statistical Claims}

Learning Outcome: Critique statistical 'claims' as made in the media/by other investigators In this topic students are provided with links to international data on mathematics and science performance of year 10 students through PISA (OECD Program for International Student Assessment) and year 4 and 8 students through TIMSS (Trends in International Mathematics and Science Study). They are asked to examine newspapers' claims about PISA data and explain in a discussion form post why they are accurate (or not) using the following questions:

- What do these data represent?

- Describe the trend(s) for Australian students over the period 2003 to 2012 for PISA data

- Are the conclusions made by the authors of the articles accurate? Why or Why not?

For the assessment of this topic, they are directed to an official report of TIMSS data on the Gapminder website and asked to choose one finding for year 4 or 8 , comparing results from 1995, 2003 and 2007, and demonstrate how the authors of the report came to this conclusion, using summary statistics and graphical representation of the data in a report of 1-2 pages. They are provided with a rubric to guide the quality of their report.

Students can refer to the previous section for assistance with calculating descriptive statistics and graphical representation of them and their answers are scaffolded by the rubric.

\section{Elaborate Phase: Using Statistical Reasoning}

Learning Outcome: Formulate a question that can be answered quantitatively and answer the question/argue the claim using statistical reasoning

In the fourth topic students are asked to undertake an investigation in a small group (2-3), choose an education- or science-related topic on the Gapminder website, find a media report that investigates the same topic/issue and examine the accuracy of the media report via statistical analysis. Students are asked to:

- Formulate a scientific (testable) question

- Identify the variables involved and data sampling strategy required

- Download the appropriate data from the Gapminder website

- Calculate descriptive statistics

- Present results graphically in a MSPowerpoint, Prezi web-based software or multimedia presentation (video)

- Make a judgement on the accuracy of the media report and support their claims with the data they have analysed

This complex activity is scaffolded by three examples of media reports that unpack others' reports and demonstrate how they have misinterpreted data and/or analyses, and then providing the correct interpretations.

\section{Evaluate Phase: Presenting and Evaluating Evidence}

Learning Outcome: Use relevant evidence: data, analysis, statistics, and interpretation 
For the evaluation of their learning about statistics students are asked to upload their group's presentation and view fellow students' group presentations, to comment in a discussion forum on at least two presentations, regarding their effectiveness in using evidence and statistical reasoning to evaluate an education or science issue reported in the media. A template and rubric are provided. They are then asked to stay in their groups to mark two of their fellow students' group presentations, provide reasons for the marks, and then reflect on how well a presentation addresses each part of the template. These reports are uploaded to an assessment dropbox.

Finally, students are asked to reflect individually (and submit to an assessment dropbox) on how they would use statistics, evidence and the evaluation of evidence differently in their personal and professional lives after completing the module, by answering the stimulus questions:

- What do you think the role of statistics is in everyday life?

- What did you do in this module that has influenced your thinking?

- In what way (if any) have your ideas about statistics changed after completing this module?

- Has your attitude to the use of statistics changed? Explain how it has changed in relation to the future impacts on your teaching.

The inquiry-based activity in the previous topic, the critical evaluation of others' reports in this final topic and the reflection on their changed understanding of statistics provide in-depth opportunities for students to develop skills in inquiry-based investigation (Bybee, 2009).

\section{MODULE TRIALLING}

After an initial review by three academics and one student, the Statistical Literacy-Primary module is undergoing trialling at the University of Western Sydney during semester 1, 2015, and at Australian Catholic University in semester 2, 2015. Preliminary feedback from the UWS tutor for the module indicates that SL-P rapidly escalates students into higher order tasks when in some cases they do not have a strong grasp of prerequisite basic disciplinary concepts of variability, sampling and causes of variation. This result has shaped the development of an introductory mathematics module, which builds understanding of numeracy concepts and applications of mathematics, before culminating in an exploration of these statistical concepts. In addition, further scaffolding about sampling and calculation of means and standard deviations in Microsoft Excel has been added to the SL-P module.

\section{CONCLUSION}

A comprehensive evaluation of the module is in its early stages following collection of tutor review, student feedback and performance data during trialling. These will provide evidence of the effectiveness of the SL-P module in terms of students' engagement with and development of statistical literacy. The outcomes of the evaluation will provide direction for revising the module, ultimately for inclusion in new teacher education programs and professional learning, in which statistical literacy is a core component.

\section{REFERENCES}

Australian Curriculum and Reporting Authority (ACARA) (2013). The Australian CurriculumScience. http://www.australiancurriculum.edu.au/science/curriculum/f-10

Australian Government, Department of Employment and Workplace Relations (2010). Regional Participation: The Role of Socioeconomic Status and Access Report. http://www.innovation.gov.au

Bower, M., Hedberg, J. G., \& Kuswara, A. (2010). A framework for Web 2.0 learning design. Educational Media International, 47, 177-198.

Braund, M., \& Reiss, M. (2006). Towards a more authentic science curriculum: The contribution of out-of-school learning. International Journal of Science Education, 12, 1373-1388.

Bybee, R. W. (2009). The BSCS 5E instructional model and 21st century skills. Paper commissioned for the Workshop on Exploring the Intersection of Science Education and the Development of 21st Century Skills. Washington: National Academies Board on Science Education. 
Chubb, I., Findlay, F., Du, L., Burmester, B., \& Kusa, L. (2012). Mathematics, Engineering and Science in the National Interest. Canberra: Australian Government, Office of the Chief Scientist.

Matthews, K., Belward, S., Coady, C., Rylands, L., \& Simbag, V. (2012). The state of quantitative skills in undergraduate science education: findings from an Australian study. Report associated with project, Quantitative Skills (QS) in Science: Curriculum model for the future. Canberra: Australian Learning and Teaching Council.

Mulligan, J., Hedberg, J., Parker, Q., Coady, C., \& Cavanagh, M. (2014). Opening Real Science: Introducing authentic scientific methodology into mathematics and science teacher preparation. Paper presented to STEM Conference, University of British Columbia, Vancouver, Canada.

Prasad, S. (2012). Science in secondary schools: Health of Australian Science. Canberra: Australian Government, Office of the Chief Scientist.

Slater, S. J., Slater, T. F., \& Shaner, A. (2008). Impact of backwards faded scaffolding in an astronomy course for pre-service elementary teachers based on inquiry. Journal of Geoscience Education, 56, 408-416.

Tytler, R. (2007). Re-imagining science education: Engaging students in science for Australia's future. Melbourne: Australian Council for Educational Research.

Ziman, J. (2000). Real science: What it is, and what it means. Cambridge: Cambridge University Press. 